\title{
Dilution and dispersion of inhalable particulate matter
}

\author{
N. A. Kgabi \& T. Mokgwetsi \\ Department of Physics, North-West University, South Africa
}

\begin{abstract}
In this study, HYSPLIT model was used to simulate the dilution and dispersion of particulate matter concentrations that were measured at three sites (RMINE, RCBD and RBPS) in the Rustenburg area. The three sites experienced average monthly dispersion of over 100, 120 and $130 \mathrm{~km}$ for RMINE, RCBD and RBPS respectively. The effect of meteorological parameters like temperature, wind speed and wind direction on aerosol dilution and dispersion was also determined. The profiles obtained showed that high wind speeds $(>11 \mathrm{~m} / \mathrm{s})$ dilute and disperse pollutants more rapid over long range; and low temperatures of 2 degree celsius or below cause pollutants to reside within a source region.

The results showed that wind speed causes more dispersion than it causes dilution whereas increase in temperature causes more dilution than dispersion; hence more dilution was observed in summer than in the winter season. The study suggests that stagnant air, often caused by an anticyclone or temperature inversion, or other lack of winds cause air pollution to remain in one area; thus causing the air quality to worsen due to lack of dilution of air emissions. An inversion can prevent the rise and dispersal of pollutants from the lower layers of the atmosphere and cause a localized air pollution problem. This study further suggests that meteorological conditions like temperature, wind speed and wind direction are the key determinants of dilution and dispersion of pollutants.
\end{abstract}

Keywords: HYSPLIT, dilution, dispersion, meteorological parameters.

\section{Introduction}

To understand air pollution, researchers should also understand the meteorology, dilution and dispersion of pollutants from the source (or sampling point) to the receptors. The dependence of air pollution on meteorology makes any air 
pollution study to be very complex and often inexact. Most researchers use modeling to better understand the complexity of the atmosphere and pollutant dispersion.

One of the fundamental reasons for modeling atmospheric transport and diffusion (ATD) is to predict the concentration in the atmosphere of hazardous material released from one or more points of release (sources) to other locations [1]. At the most basic level, an ATD model predicts the motion of aerosols in the atmosphere, the wind and turbulence fields, and transport and diffusion of the material of interest after its release. Inherent constraints often arise from limited information about the source, the atmosphere, and the time available to generate a prediction. The information needed about the source and the state of the atmosphere is always limited [1].

High wind speeds $(24 \mathrm{~km} / \mathrm{h}$ or greater) tend to disperse pollutants and prevent their accumulation. At these speeds, the amount of dispersion outweighs the transport effects, and high concentrations are unlikely to occur anywhere. Air, however, also travels in vertical directions. When vertical wind speeds are high, pollutants are dispersed vertically and do not become concentrated at the ground [2]. Very light winds or no wind, such as those in a strong high pressure system, can be a problem for urban areas, because all the pollution that a city creates is not dispersed [3].

The objective of this study is to determine the dilution and dispersion of inhalable particulate matter (PM10) concentrations measured in Rustenburg mining areas; and the effect of meteorological parameters like Temperature, Wind Speed and Wind Direction on aerosol dilution and dispersion.

Hybrid Single-Particle Lagrangian Integrated Trajectory (HYSPLIT) model was used to simulate dilution and dispersion in the Rustenburg area of the North West province. HYSPLIT is being used with increased frequency in large scale research studies. HYSPLIT is an analysis model that is capable of modeling air mass trajectories, as well as the particle dispersion and deposition simulations [4]. Dispersion of a pollutant is calculated by assuming either puff or particle dispersion. In the puff model, puffs expand until they exceed the size of the meteorological grid cell (either horizontally or vertically) and then split into several new puffs, each with its share of the pollutant mass [7]. In the particle model, a fixed number of initial particles are advected about the model domain by the mean wind field and a turbulent component. The model's default configuration assumes a puff distribution in the horizontal and particle dispersion in the vertical direction [4]. In this way, the greater accuracy of the vertical dispersion parameterization of the particle model is combined with the advantage of having an ever expanding number of particles representative of the pollutant distribution. The current version of HYSPLIT is designed to create one trajectory at a time [5].

The HYSPLIT model calculation method is a hybrid between Eulerian and Lagrangian approaches. In the Eulerian modeling approach, air concentrations are computed for every grid cell by integrating the pollutant fluxes at each grid cell interface due to diffusion and advection. In the Lagrangian modeling approach, air concentrations are computed by summing the contribution of each 
pollutant puff that is advected through the grid cell as represented by its trajectory [8].

\section{Experimental}

Sampling of PM10 was done at three sites namely; RMINE with latitude $25^{\circ} 43^{\prime} 03,0^{\prime \prime} \mathrm{E}$ and longitude $27^{\circ} 23^{\prime} 57,8^{\prime \prime} \mathrm{S}, \mathrm{RCBD}$ with latitude $25^{\circ} 40^{\prime} 01,3^{\prime \prime} \mathrm{E}$ and longitude $27^{\circ} 16^{\prime} 38,5^{\prime \prime} \mathrm{S}$, and RBPS with latitude $25^{\circ} 30^{\prime} 15^{\prime \prime} \mathrm{E}$ and longitude $27^{\circ} 5^{\prime} 45^{\prime \prime} \mathrm{S}$ as shown as A, B and C respectively in Figure 1.

The sampling period for the three sites was from February to June 2004, June to December 2004 and August to December 2004 respectively. The meteorological data at these sites was provided by South African Weather Service (SAWS) [6].

In order to simulate the dispersion for PM10, meteorological data was entered into the model using Graphic User Interface (GUI) of HYSPLIT installed in a Personal Computer (PC). Upon running HYSPLIT4, the GUI menu opened with four different menus: the Meteorology menu, Trajectory menu, Concentration menu, and the Advanced menu.

The meteorology menu was used specifically for meteorological parameters like wind speed, wind direction, mixing layer and stability. The advanced menu setup was used for simulation setup where limits for particles released per cycle, maximum number of particles, setting emission cycling parameters, and other simulating settings were defined.

The concentration setup menu was used to setup concentrations by specifying the locations, grid size, pollutant mass, emission rate, precipitation, particle size and other parameters.

\section{Discussion of results}

\subsection{Dilution and dispersion at RMINE}

The hourly dilution and dispersion of PM10 at RMINE on 29 May 2004 is shown in Figure 2. Generally, there is slow movement by pollutants as they only disperse to a short distance which is a radius of not more than $27 \mathrm{~km}$ from the source, and might be the effect of wind direction. The wind was blowing from $\mathrm{NNW}$ at the speed of $8.7 \mathrm{~m} / \mathrm{s}$. One would expect the dispersion to be in the SSE direction instead of NNE.

The average monthly profile for March to June 2004 is shown in Figure 3. The dispersion occurs more to the South of South Eastern (SSE) direction. From the source to over $100 \mathrm{~km}$ concentrations of particles is noted to be high as indicated by yellow coloring. This could be due to the fact that during March and April there was some form of precipitation $(11 \mathrm{ml}$ for March and $27.4 \mathrm{ml}$ for April rain, refer to Table 1) and that from May through June is winter period with low temperatures (between $1{ }^{\circ} \mathrm{C}-20^{\circ} \mathrm{C}$ ). The two parameters normally cause particles to be denser and heavier, thus yielding slow dilution of particles. 


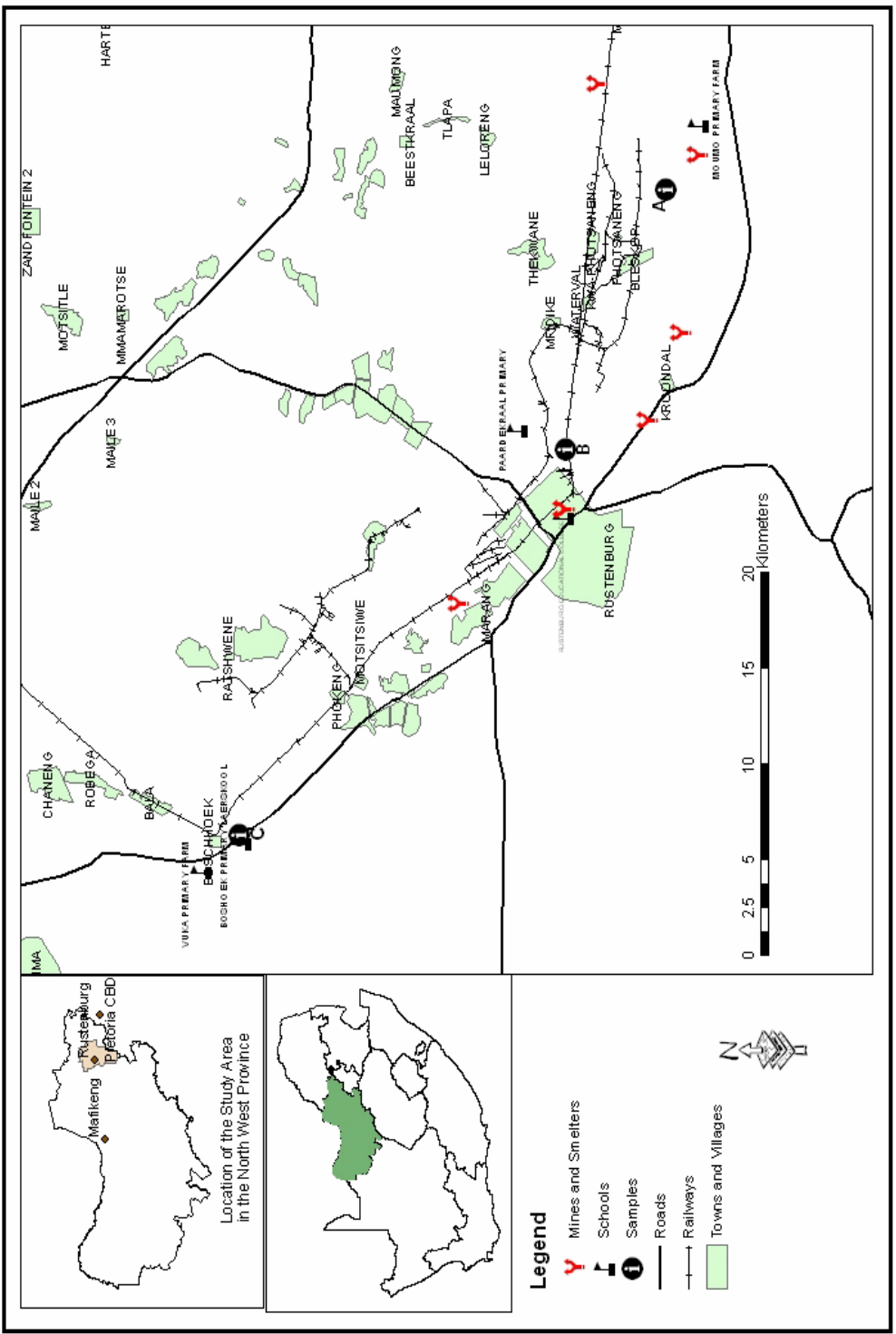


Management of Natural Resources, Sustainable Development and Ecological Hazards II 233

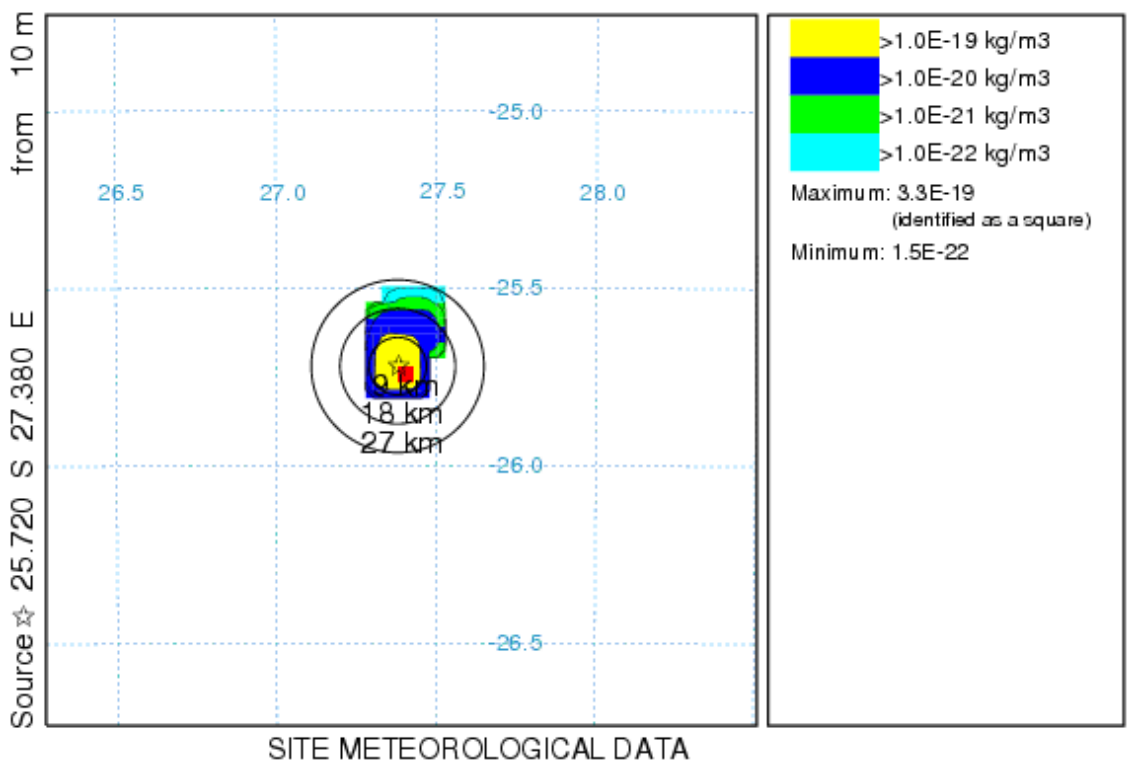

Figure 2: $\quad$ Hourly dilution and dispersion at RMINE - 29 May 2004.
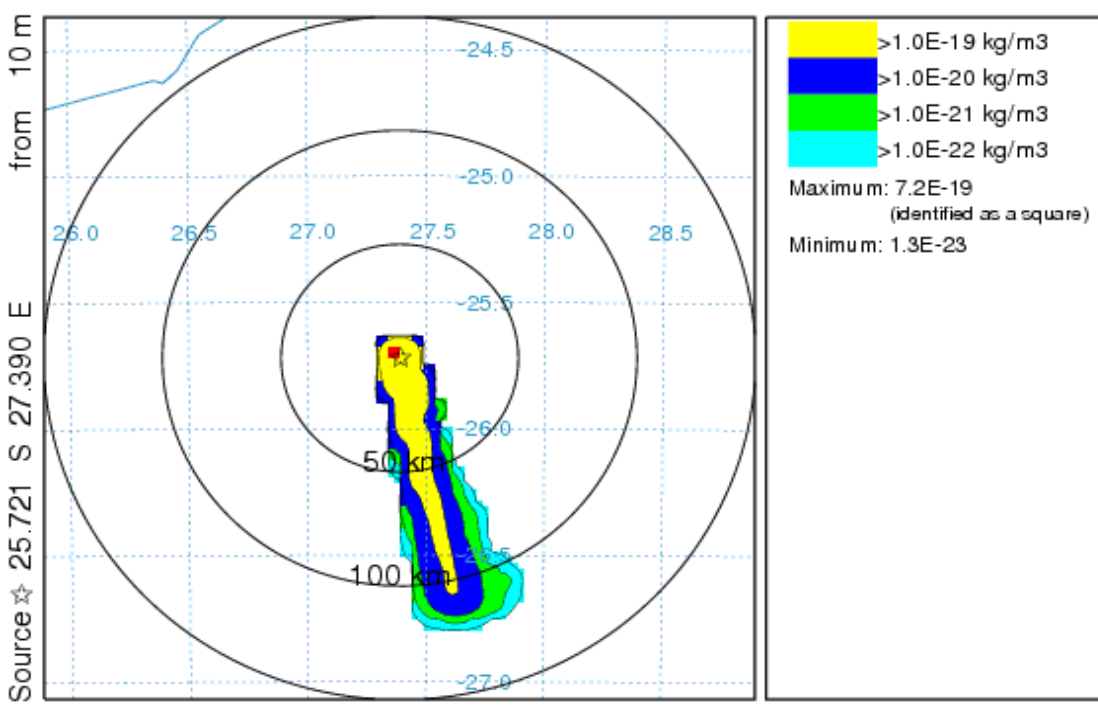

Minimu m: 1.3E-23

Figure 3: $\quad$ Monthly dilution and dispersion at RMINE - Mar to Jun 2004. 
Table 1: Monthly average meteorological data for the Rustenburg area supplied by the South African Weather Services (SAWS).

\begin{tabular}{|c|c|c|c|c|c|c|}
\hline \multirow[t]{2}{*}{ Season } & \multirow[t]{2}{*}{ Month } & \multicolumn{2}{|c|}{$\begin{array}{l}\text { Temperature } \\
\left({ }^{\circ} \mathrm{C}\right)\end{array}$} & $\begin{array}{l}\text { Rainfall } \\
\text { (ml) }\end{array}$ & \multirow{2}{*}{$\begin{array}{l}\text { Wind } \\
\text { Speed } \\
(\mathrm{m} / \mathrm{s})\end{array}$} & \multirow{2}{*}{$\begin{array}{l}\text { Wind Direction } \\
\text { (Degrees from } \\
\text { true North) }\end{array}$} \\
\hline & & Min & Max & & & \\
\hline \multirow[t]{2}{*}{ Autumn } & Mar -04 & 14.7 & 25.9 & 11.0 & 15.5 & 347 (NNW) \\
\hline & Apr -04 & 12.4 & 25.4 & 27.4 & 16.3 & 337 (NNW) \\
\hline \multirow[t]{3}{*}{ Winter } & May -04 & 7.0 & 24.3 & 0.2 & 8.7 & 337 (NNW) \\
\hline & Jun -04 & 2.7 & 19.4 & 5.2 & 12.2 & 354 (NNW) \\
\hline & Jul -04 & 1.0 & 19.6 & 0.0 & 13.3 & $349(\mathrm{~N})$ \\
\hline \multirow[t]{3}{*}{ Spring } & Aug -04 & 6.5 & 23.8 & 1.6 & 15.7 & $349(\mathrm{~N})$ \\
\hline & Sep -04 & 7.5 & 25.7 & 0.2 & 16.7 & $340(\mathrm{NNW})$ \\
\hline & Oct -04 & 12.5 & 28.8 & 39.4 & 9.4 & $176(\mathrm{~S})$ \\
\hline \multirow[t]{3}{*}{ Summer } & Nov -04 & 15.3 & 31.5 & 38.2 & 10.2 & 165 (SSE) \\
\hline & Dec -04 & 16.0 & 29.2 & 83 & 10.4 & 163 (SSE) \\
\hline & Jan -05 & 17.4 & 29.4 & 160 & 9.0 & 204 (SSW) \\
\hline \multirow[t]{3}{*}{ Autumn } & Feb - 05 & 16.5 & 29.7 & 78.6 & 8.5 & 161 (SSE) \\
\hline & Mar - 05 & 14.1 & 27.3 & 42.4 & 8.8 & $190(\mathrm{~S})$ \\
\hline & Apr -05 & 11.5 & 23.2 & 91 & 7.3 & 196 (SSW) \\
\hline \multirow[t]{3}{*}{ Winter } & May - 05 & 6.4 & 23.5 & 0.8 & 6.7 & $188(\mathrm{~S})$ \\
\hline & Jun -05 & 4.4 & 22.6 & 0.0 & 6.8 & 205 (SSW) \\
\hline & Jul - 05 & 2.8 & 22.0 & 0.0 & 6.0 & 164 (SSE) \\
\hline
\end{tabular}

The concentration profile shows pollutants dispersing towards SSE, and the wind blowing from NNW to SSE at $13.2 \mathrm{~m} / \mathrm{s}$. This encouraged high dilution and dispersion of particles.

The school which is located towards the SE direction of the source may act as a receptor to the $1 \times 10^{-10} \mu \mathrm{g} / \mathrm{m}^{3}$ pollutants traveling a distance more than $100 \mathrm{~km}$.

\subsection{Dilution and dispersion at RCBD}

Dilution and dispersion of daily concentrations for September month at RCBD is shown in Figure 4.

The sampling point at RCBD is situated $2-2.5 \mathrm{~km}$ east of the closest mine. The figure shows the dispersion of pollutants that develop into two puffs moving towards the South. Rapid dilution of concentrated particles occurred within 10 $\mathrm{km}$ or less from the source/sampling point. The blue area shows concentration of about $1 \times 10^{-10} \mu \mathrm{g} / \mathrm{m}^{3}$ which disperse over $60 \mathrm{~km}$ south. The one puff moves towards SSE whereas the other moves towards SSW direction. The overall pollutants disperse to over $120 \mathrm{~km}$ south.

Most of dispersed particles are less concentrated $\left(>1.0 \times 10^{-12} \mu \mathrm{g} / \mathrm{m}^{3}\right)$. This is influenced mostly by high temperatures (above $22^{\circ} \mathrm{C}$ ) which contribute to high dispersion of pollutants [2].

From the source, the dispersion is towards the south, which suggests that it may not necessarily affect the communities nearby. The low pollutant concentrations observed may be the result of high temperatures and wind. 

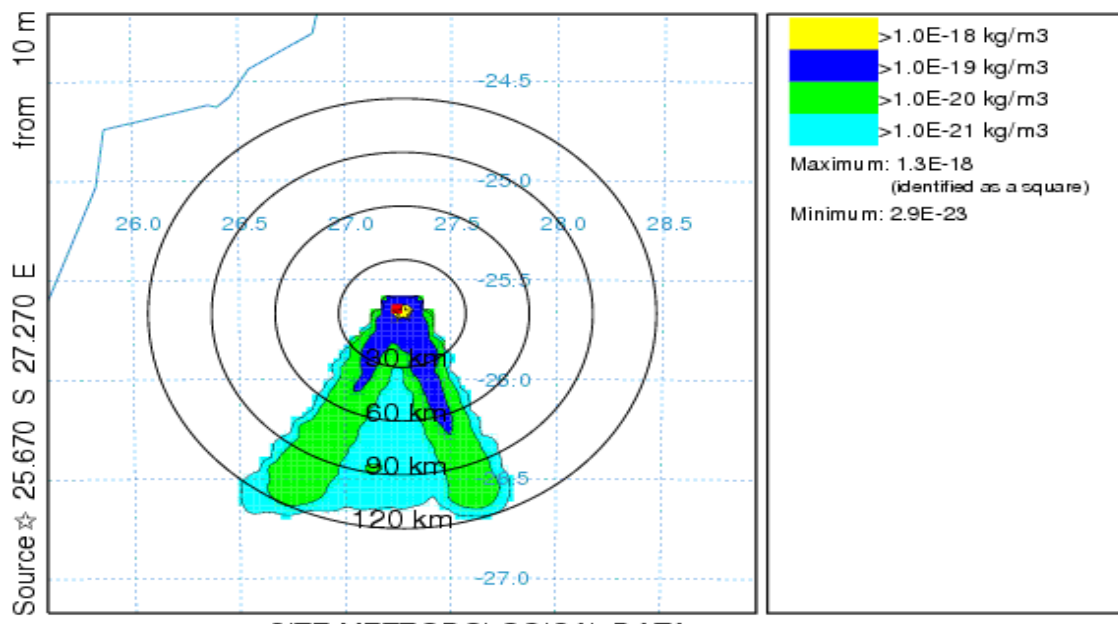

SITE METEOROLOGICAL DATA

Figure 4: Daily dilution and dispersion at RCBD - Sep 2004.
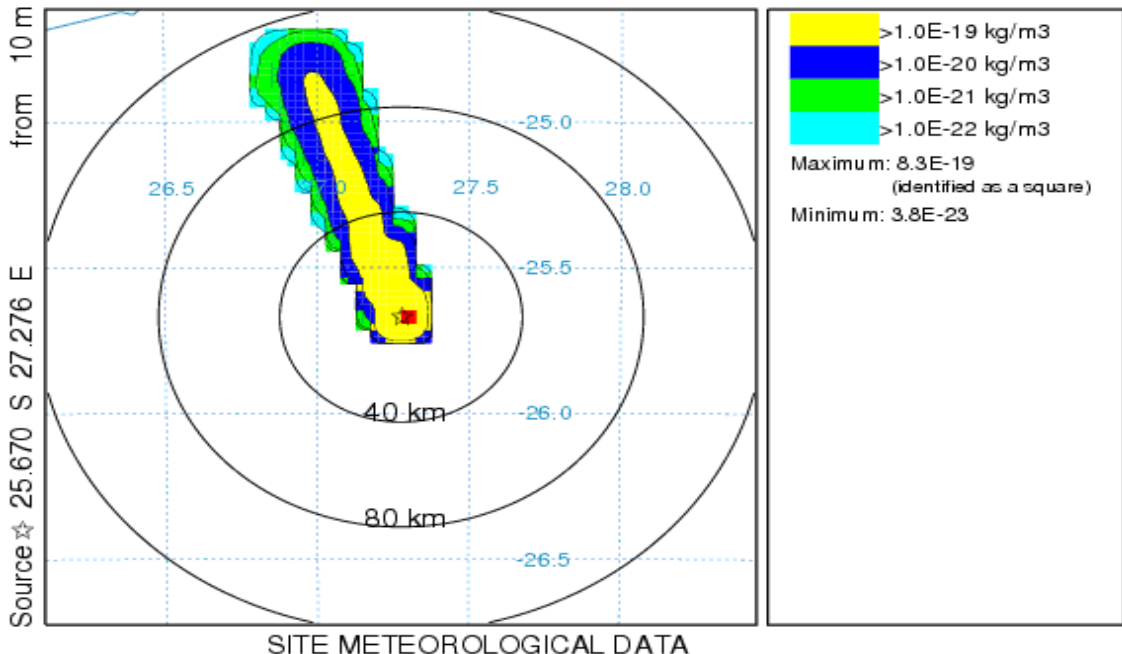

Figure 5: Monthly dilution and dispersion at RCBD - Jun to Dec 2004.

Monthly dilution and dispersion for June to December 2004 in Figure 5 suggests that particles disperse more towards NNW direction, over a distance of about $100 \mathrm{~km}$ from the sampling point. Strong wind speed $(42 \mathrm{~km} / \mathrm{h})$ and warm temperature $\left(24^{\circ} \mathrm{C}\right.$ on average) could account for the high dispersion observed.

Figure 5 shows monthly concentrations with wind direction of 271 degrees (west), wind speed of $12.6 \mathrm{~m} / \mathrm{s}$, minimum temperature of $8.7^{\circ} \mathrm{C}$ and maximum temperature of $25.4^{\circ} \mathrm{C}$. 
The profile shows the dispersion towards the Marang residential area. More particles with $1 \times 10^{-10} \mu \mathrm{g} / \mathrm{m}^{3}$ travel to more than $80 \mathrm{~km}$ which could have an effect on those areas situated in the NNW direction. This implies that communities around areas like Motsitsinye and Phokeng (Figure 1) can also be affected.

\subsection{Dispersion and dilution at RBPS}

Hourly dilution and dispersion profile of PM10 particles during the period 3 to 31 March 2005 within the Rustenburg area is given in Figure 6. Dispersion of particles over a $160 \mathrm{~km}$ distance from the source is observed even though more dense particles can be seen to cover a distance of not more than $55 \mathrm{~km}$ from the source.

Relatively strong winds (speed of $31.4 \mathrm{~km} / \mathrm{h}$ ) dilute more concentrated pollutants from the sampling point while lower temperatures (Less than $16^{\circ} \mathrm{C}$ ) cause the dilution to be slow. Average monthly concentration levels shown in Figure 7 from August 2004 to January 2005

The figure shows that the dispersion is moving towards SSE direction. The pollutants measured may have little or no effect on the Boshoek area, which is situated directly to the north of the source since the wind direction of 239 degrees (WSW) is almost opposite to the direction of dispersion.

The Phokeng area, situated in the SSE direction, will however, be affected by pollutants traveling a distance of more than $100 \mathrm{~km}$ although the effects on the community may be minimal due to rapid dilution $\left(1 \times 10^{-11} \mu \mathrm{g} / \mathrm{m}^{3}\right)$.

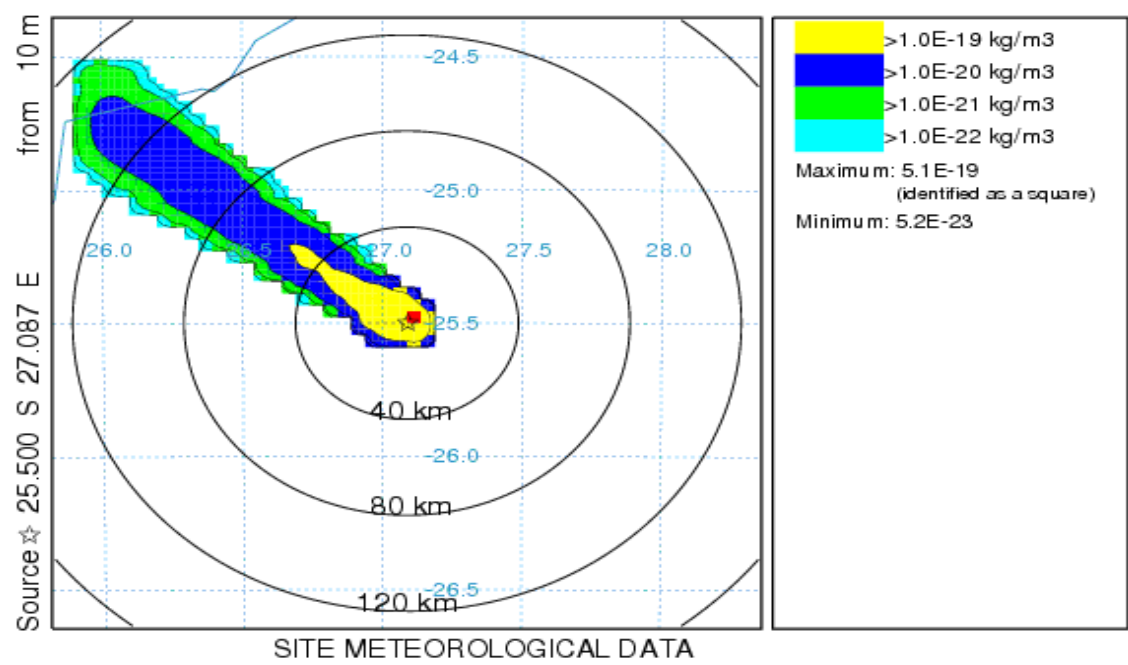

Figure 6: Hourly dilution and dispersion at RBPS - 03 to 31 Mar 2005. 

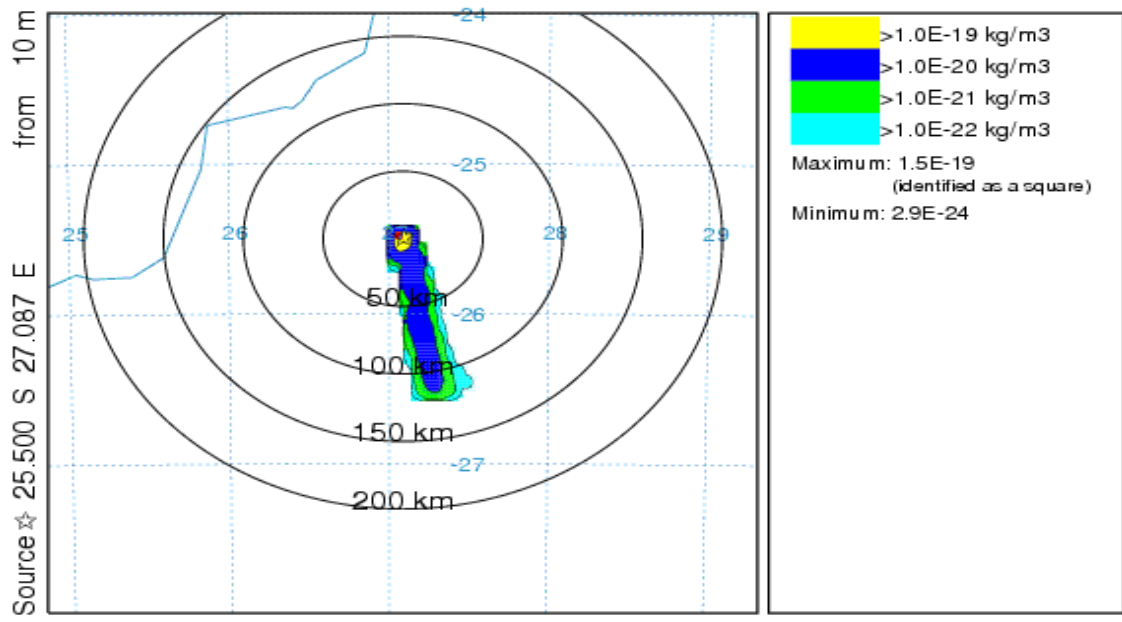

SITE METEOROLOGICAL DATA

Figure 7: Average monthly dilution and dispersion at RBPS - Aug 2004 to Jan 2005.

\section{Conclusion}

The results of this study suggest that meteorological conditions like temperature, wind speed and wind direction, have an impact on the dilution and dispersion of pollutants. Low temperatures give rise to high concentration levels whereas high temperatures favor dilution of pollutants.

RMINE experienced dispersion over a distance of $100 \mathrm{~km}$ for the monthly averages. RCBD experienced dispersion over a $120 \mathrm{~km}$ distance and Site $\mathrm{C}$ over $130 \mathrm{~km}$ distance, also using the monthly average concentrations. This study showed that dispersion is high at RBPS compared to the other two sites (RMINE and RCBD).

High temperatures $\left(>=24^{\circ} \mathrm{C}\right)$ cause more dilution; and high wind speeds $(>$ $12 \mathrm{~m} / \mathrm{s}$ ) favor both the dilution and dispersion of pollutants.

The results showed that wind speed causes more dispersion than it causes dilution whereas increase in temperature causes more dilution than dispersion; hence more dilution was observed in summer than in the winter season. The study further suggests that stagnant air, often caused by an anticyclone or temperature inversion, or other lack of winds cause air pollution to remain in one area; thus causing the air quality to worsen due to lack of dilution of air emissions. An inversion can prevent the rise and dispersal of pollutants from the lower layers of the atmosphere and cause a localized air pollution problem. It is evident from the results discussed that meteorological conditions like temperature, wind speed and wind direction are the key determinants of dilution and dispersion of pollutants. 


\section{References}

[1] Walter, D., \& Bach J., Federal Research and Development Needs and Priorities for Atmospheric Transport and Diffusion Modeling, Office of Federal coordinator for meteorological services, Silver Spring, Dec 2004.

[2] USDA, Air Quality Images Interpreting Visibility Data, http://www.fsvisimages.com/visdata.html, November 2007.

[3] EPA, NOAA, US National Weather Service, Air Quality Awareness, http://www.epa.gov/airnow/airaware/day2-detail.html, January 2008.

[4] Draxler, R.R., \& Hess G.D., Description of the HYSPLIT 4 Modeling System. NOAA Technical memo ERL ARL - 224, December 1997

[5] Heinzerling D., Automation of HYSPLIT Trajectory Generation and subsequent Analysis, Washington University, 2004

[6] South African Weather Services (SAWS), http://www.saws.co.za

[7] Draxler, R.R., Hysplit_4 User's Guide, NOAA Air Resources Laboratory, 1998

[8] Draxler, R.R., HYSPLIT PC TRAINING SEMINAR, National Oceanic and Atmospheric Administration, 10 June 2004 